\title{
Pathogenicity of Phytophthora lateralis Lineages on Different Selections of Chamaecyparis lawsoniana
}

C. Robin, INRA, UMR 1202 Biogeco, 33612 Cestas Cedex, France; and Univ. Bordeaux, BIOGECO, UMR1202, F-33400 Talence, France; C. Brasier, Forest Research, Alice Holt Lodge, Farnham, Surrey GU10, UK; P. Reeser and W. Sutton, Department of Botany and Plant Pathology, Oregon State University, Corvallis; A. Vannini and A. M. Vettraino, Department for Innovation in Biological, Agro-food and Forest Systems (DIBAF), University of Tuscia, 01100 Viterbo, Italy; and E. Hansen, Department of Botany and Plant Pathology, Oregon State University, Corvallis

\begin{abstract}
Robin, C., Brasier, C., Reeser, P., Sutton, W., Vannini, A., Vettraino, A. M., Hansen, E. 2015. Pathogenicity of Phytophthora lateralis lineages on resistant and susceptible selections of Chamaecyparis lawsoniana. Plant Dis. 99:1133-1139.

Phytophthora lateralis, the cause of Chamaecyparis lawsoniana root disease, was introduced in North America about 1920, and has since killed trees along roads and streams throughout the tree's range. Recent results suggest an Asian origin for this oomycete and four genetic lineages were identified. This raised questions for the genetic exapted resistance demonstrated in 1989 within the wild population of C. lawsoniana but with only one $P$. lateralis lineage. The main goal of the present research was to test the durability of the demonstrated resistance and to

compare the pathogenicity of isolates representing the four lineages. No breakdown of resistance was observed in five separate tests using different inoculation techniques, resistant and susceptible $C$. lawsoniana trees, and seedling families. Differences in mortality and lesion length were observed between the lineages. The higher aggressiveness of isolates of the TWJ and PNW lineages and the lower aggressiveness of the TWK lineage are discussed in view of the hypotheses on the history of spread and evolutionary history of the $P$. lateralis lineages.
\end{abstract}

Chamaecyparis lawsoniana (Port Orford cedar [POC] or Lawson's cypress) is an ecologically and economically valuable forest tree native to southwest Oregon and northern California $(19,21)$. Because of its attractive and variable growth form it became an important horticultural species, with many cultivars propagated in nurseries and widely planted in landscapes in North America and Europe (21).

Phytophthora lateralis is an exotic, invasive pathogen that has had a severe impact in native Chamaecyparis lawsoniana forests, landscape plantings, and horticultural nurseries in western North America $(6,9,17)$. It has also recently established multiple times in the European landscape, first in France and the Netherlands $(8,10,13)$, then in Scotland, England, and Northern Ireland (4). The pathogen spreads readily in contaminated soil and surface water $(6,9)$. Aerial infections observed first in France suggest that in landscape plantings in Europe especially, it also could spread through airborne sporangia $(4,13,16)$. $P$. lateralis is classified on the European Plant Protection Organization A2 List (EPPO 2009) of pests recommended for regulation as quarantine pests that should be considered with caution and for which we need to develop management methods, including trees resistant to the pathogen on both continents.

Until recently the origin of the pathogen was unknown, although suspicion centered on eastern Asian forests and their native Chamaecyparis species, which are resistant or tolerant of infection, at least in landscape plantings in the western United States $(6,13)$. The disease was first recognized in nurseries in the Pacific Northwest (PNW) of North America in 1923 (21) and was established in the native POC forest in southwest Oregon and northern California by 1952 (14). In 2008 and again in $2010(2,20)$, P. lateralis was isolated in natural old growth forests of $C$. obtusa in Taiwan, supporting arguments for an Asiatic origin for this species. A comparison of morphological features, growth, and phylogenetic relationships revealed at least four phenotypically distinct evolutionary lineages among isolates

Corresponding author: E. Hansen, hansene@science.oregonstate.edu.

Accepted for publication 12 October 2014.

http://dx.doi.org/10.1094/PDIS-07-14-0720-RE

(C) 2015 The American Phytopathological Society of $P$. lateralis worldwide, designated the PNW, UK, TWK, and TWJ lineages (1), summarized in Table 1. Isolates from the PNW of North America and most European isolates comprise the PNW lineage. These are fast growing with larger sporangia and chlamydospores. Two lineages, TWJ and TWK, are presently known only from Taiwan. Both are slow growing but TWK has relatively small spores whereas TWJ, like the PNW lineage, has larger spores. TWJ isolates sometimes cluster with PNW in the molecular phylogeny. The UK lineage is of intermediate growth rate, with often unusually narrow elongated sporangia and is presently known only from western Scotland.

Although $C$. lawsoniana has not evolved with $P$. lateralis, it is the source of exapted resistance to this oomycete. Genetic resistance within the wild population of $C$. lawsoniana was demonstrated in 1989 (7). Cedar trees that survived epidemics in the wild or in artificially infested raised beds have been tested for their resistance to $P$. lateralis using a variety of inoculation procedures (5). A program was initiated by the Dorena Genetic Resource Center (DGRC) USDA Forest Service (http://www.fs.usda.gov/goto/r6/dorena) in cooperation with Oregon State University (OSU) to develop this genetic resistance in $C$. lawsoniana through conventional breeding and to use resistant trees in seed orchards with the goal of providing resistant seedlings for forest regeneration $(15,18)$. In repeated tests by DGRC and OSU, most POC trees prove very susceptible; susceptible seedling families showed only 0 to $10 \%$ survival using a variety of inoculation techniques. Rooted cuttings of resistant parents were seldom killed, and seedling families of these parents exhibited 25 to $100 \%$ survival, depending on family and inoculation technique (12).

The main goal of the present research was to test the durability of the demonstrated resistance when challenged by the new isolates and lineages of $P$. lateralis from Europe and Taiwan. In five separate tests using different inoculation techniques, resistant and susceptible $C$. lawsoniana trees and seedling families were challenged by isolates of $P$. lateralis representing all four lineages (Table 2 ). Additional goals were to confirm pathogenicity of the lineages and to test for host genotype $\times$ pathogen genotype (lineage) interactions including whether any of the newly described lineages of $P$. lateralis could overcome the resistant selections from the DGRC program. 


\section{Materials and Methods}

Phytophthora lateralis isolates. Origin, lineage (as defined by phenotypic and genetic characteristics in (1)), and the tests in which the $16 P$. lateralis isolates were used are listed in Table 3. Isolates were grown on homemade corn meal agar amended with $\beta$-sitosterol (CMAB) (15 g Bacto agar, $50 \mathrm{ml}$ corn steep, $20 \mathrm{mg} \beta$-sitosterol). Corn steep was made by mixing $100 \mathrm{~g}$ yellow corn meal in $650 \mathrm{ml}$ deionized water at $60^{\circ} \mathrm{C}$ for $1 \mathrm{~h}$, then filtering to remove solids. Cultures were maintained in water storage in the culture collection at OSU.

To produce zoospores, isolates were grown for 1 week on CMAB, then three $3 \mathrm{~mm}$ diameter plugs cut from the advancing edge of colonies were transferred to pea broth ( $150 \mathrm{~g}$ dry split peas per liter, autoclaved for $3 \mathrm{~min}$ and strained through a double layer of cheesecloth, then autoclaved for $60 \mathrm{~min}$ at $121^{\circ} \mathrm{C}$ ) and grown for 7 days. The culture medium was removed and plates were rinsed with deionized water, then filled with $10 \mathrm{ml}$ filtered, unsterile water from a local stream. After $24 \mathrm{~h}$ (or $48 \mathrm{~h}$ for TWK isolates where sporangia were slow to form), zoospore release was triggered, if needed, by chilling plates $1 \mathrm{~h}$ at $5^{\circ} \mathrm{C}$, then returning to room temperature. Zoospore concentrations were measured with hemacytometer and varied between tests and isolates between about $5 \times 10^{3}$ and $5 \times 10^{5} / \mathrm{ml}$.

Plant material. Clonal material and seedling families, described in Table 4, were selected for this study from the POC resistance program to represent different modes and levels of resistance to $P$. lateralis isolates from Oregon and California, as determined in earlier work $(5,12)$.

Resistant and susceptible "control" trees (Table 4) and seedling families are included in all resistance screening trials at DGRC and were included here. Parent trees, originally propagated from rooted cuttings, were maintained in the cedar clone bank at the Bureau of Land Management Tyrrell seed orchard in Oregon (15). Resistant control parent tree 117490 is highly resistant in repeated tests; rooted cuttings are seldom killed by the pathogen, and seedling progeny, whether from self-pollination or from control crosses with known susceptible parents, are also resistant. The pattern is consistent with parent 117490 being homozygous for a single dominant gene for resistance (11). Histological responses in inoculated seedlings suggest a hypersensitive reaction (11). Clonal material of parent OSU-CF1 responds like 117490 to challenge inoculation, but seedling families from crosses with susceptible parents appear to segregate for

Table 1. Summary of the basic properties of the Phytophthora lateralis lineages $^{\mathrm{a}}$

\begin{tabular}{|c|c|c|c|c|}
\hline Lineage & PNW & TWJ & TWK & UK \\
\hline Growth rate & fast & slow & slow & intermediate \\
\hline Sporangia & large & large & small & elongated \\
\hline Chlamydospores & large & large & small & variable \\
\hline Colony pattern(s) & unique & unique & unique & unique \\
\hline Known distribution & $\begin{array}{l}\text { USA (OR, CA, } \\
\text { WA, BC), France, } \\
\text { Netherlands, United } \\
\text { Kingdom }\end{array}$ & Taiwan & Taiwan & $\begin{array}{l}\text { west } \\
\text { Scotland }\end{array}$ \\
\hline
\end{tabular}

${ }^{a}$ Based on Brasier et al. (2012). resistance consistent with $\mathrm{CF} 1$ being heterozygous for a single resistance gene (Sniezko, personal communication). Resistance in parent 510005 is not so well characterized as 117490 or CF1. Susceptible control trees included OSU CON-1 and OSU SUSC-2. Both are unselected mature trees that survive on the OSU campus, and have been vegetatively propagated in the Tyrrell orchard. The remaining seedling families were included because they showed intermediate survival between resistant and susceptible control families in previous tests. In most cases, these families exhibited a "slow-to-die" phenotype, suggesting a degree of tolerance to infection. Wild type seedlings are 2-year-old seedlings, grown from open-pollinated seed collected from unselected forest trees in southwest Oregon. These seedlings have variable phenotypes, but nearly all are susceptible.

Pathogenicity tests. Five different pathogenicity tests were conducted with isolates of the several $P$. lateralis lineages (Table 2). Tests 1 and 2 used stem wound inoculation of unselected, wild type seedlings to measure differences in aggressiveness among the lineages. Tests 3, 4, and 5 used zoospore inoculation of cut branches or roots of intact seedlings from known resistant or susceptible POC trees to test for differences in virulence among the lineages.

Stem wound inoculation (Tests 1 and 2). Test 1 challenged unselected, wild type POC seedlings with stem wound mycelial inoculation. Two-year-old seedlings were inoculated in summer 2011 with mycelium from $10 P$. lateralis isolates representing the PNW lineage from the United States and France and the TWK lineage from Taiwan (Table 3). Seedlings averaged $1 \mathrm{~cm}$ diameter at the inoculation point. Ten seedlings were inoculated with each isolate or a control. Agar plugs, $5 \mathrm{~mm}$ in diameter, were removed from the advancing mycelial front of colonies grown on CMAB agar. Seedlings were wounded by cutting a U-shaped flap with a scalpel through the bark and inserting a mycelial plug. Wounds were about $1 \mathrm{~cm}$ long and were wrapped with moist gauze and sealed with Parafilm and foil. Control seedlings were wounded but inoculated with a sterile $\mathrm{CMAB}$ block. After 2 weeks at ambient temperature $\left(23\right.$ to $28^{\circ} \mathrm{C}$, mean $\left.24.5^{\circ} \mathrm{C}\right)$ and light, bark was scraped and length of any necrotic lesion, including the wound length, was measured. Girdling, indicated by growth of the lesion completely around the stem, was noted.

Test 2, completed in 2012, used seedlings and inoculation methods similar to Test 1 , except that lesion lengths were measured after 19 days incubation at $18^{\circ} \mathrm{C}$ with a 12-h light cycle. Seven isolates representing the PNW lineage from the United States and France, the TWJ lineage from Taiwan, and the UK lineage were compared (Table 3). Nine seedlings were inoculated with each isolate or a control.

Zoospore inoculation (Tests 3, 4, and 5). Test 3 challenged clonal cuttings from resistant and susceptible control trees with zoospore inoculation comparing six PNW lineage isolates, three TWK isolates, and an uninoculated (water only) control (Table 3). Cut ends of branch tips from five trees ( 15 years old, grown from rooted cuttings and selected for resistance or susceptibility (Table 4)) were immersed in zoospore suspension and subsequent lesion lengths measured, with 10 replicate branches per treatment. Branch tips, each about $30 \mathrm{~cm}$ long, were clipped from each candidate tree, labeled, and transported cool and moist to the OSU lab for testing. Zoospores were induced as described above. The water containing the colonies and zoospores was poured from plates into 1 liter glass inoculation

Table 2. Summary of pathogenicity tests challenging resistant and susceptible selections of Port Orford cedar with isolates representing four lineages of $P$. lateralis

\begin{tabular}{|c|c|c|c|c|}
\hline Test & Objective & Lineages & POC materials & Measured variable \\
\hline Test 1 - Stem wound inoculation & Aggressiveness & PNW, TWK & Wildtype & Lesion length \\
\hline Test 2 - Stem wound inoculation & Aggressiveness & PNW, TWJ, UK & Wildtype & Lesion length \\
\hline Test 3 - Zoospore dip inoculation & Virulence and aggressiveness & PNW, TWK & $\begin{array}{l}\text { Clonal branch tips, resistant and } \\
\text { susceptible trees }\end{array}$ & Lesion length \\
\hline Test 4 - Zoospore dip inoculation & Virulence and aggressiveness & PNW, TWK, UK & $\begin{array}{l}\text { Seedlings from resistant and } \\
\text { susceptible trees }\end{array}$ & Time to death \\
\hline Test 5 - Zoospore dip inoculation & Virulence and aggressiveness & PNW, TWK, TWJ, UK & $\begin{array}{l}\text { Seedlings from resistant and } \\
\text { susceptible trees }\end{array}$ & Time to death \\
\hline
\end{tabular}


jars. Water and zoospores of each isolate along with additional water to total $40 \mathrm{ml}$ were combined in each jar to an approximate depth of $1 \mathrm{~cm}$. The volume of zoospore suspension added to each jar was adjusted to give a zoospore concentration in the inoculation jars between $2 \times 10^{5}$ and $1 \times 10^{6}$ per $40 \mathrm{ml}$. Branches were freshly trimmed to 20 to $30 \mathrm{~cm}$ length, mixed among the trees, clustered in bundles of 10, then placed cut end down in each glass jar with zoospores, care being taken to insure that each cut end was immersed. Branches remained with cut ends in the zoospore suspension for $24 \mathrm{~h}$, and then were transferred individually to plastic growth tubes filled with wet vermiculite. Additional branches were placed in water without zoospores. Racks of test cuttings were held at $18^{\circ} \mathrm{C}$ with a 12-h light cycle and watered regularly. After 3 weeks, each branch tip was removed from the vermiculite, rinsed, and scraped at the cut end to reveal the discolored lesion in the inner bark. Lesion length was recorded.

In tests 4 and 5, root tips of intact 9-month-old seedlings were inoculated with zoospores of $P$. lateralis, and the time to seedling death was recorded. Seedlings were grown in individual $3.8 \mathrm{~cm}$ top diameter, $21 \mathrm{~cm}$ length 'supercell' plastic tubes (Cone-tainer) until roots emerged from the bottom of the growth tubes. Emergent roots were trimmed immediately prior to inoculation. Seedlings of different families were mixed and inoculated in groups of six or seven in plastic tubs. The lower $1 \mathrm{~cm}$ of the root system (in the growth tube) was immersed in a $P$. lateralis zoospore suspension from a particular isolate (prepared as above) for $24 \mathrm{~h}$. The inoculated trees were then incubated at 18 to $19^{\circ} \mathrm{C}$ with a 12-h light cycle for 27 (test 4) or 21 weeks (test 5) and symptom development was periodically recorded. At the first sign of yellowing or wilting, a small slice in the bark at soil level was made and the stem examined for the characteristic necrotic lesion caused by $P$. lateralis. Mortality, evidenced by diagnostic lesion at the ground line, was noted regularly and the days from inoculation to mortality recorded. Some seedlings were killed by root weevils; seedlings with this characteristic girdling injury were removed from the analysis. In test 4 , seven isolates of $P$. lateralis representing three lineages (Table 3) were compared on eight or 10 replicate seedlings of each of 10 seedling families of known parentage (Table 4). In test 5 , eight to 10 seedlings of each of seven POC families were inoculated with each of seven $P$. lateralis isolates, representing all four lineages.

Reisolations and PCR diagnostics. Reisolations and PCR diagnostics were performed to confirm the presence of $P$. lateralis in stem necrotic lesions, observed after mycelial (tests 1 and 2) or zoospore (tests 3 to 5) inoculations. The protocols previously described (12) were used.

Statistical analyses. Analysis of variance was performed to test for differences in lesion lengths in $C$. lawsoniana plants between $P$. lateralis isolates (fixed effect, tests 1, 2, and 3) and between host trees (fixed effect, test 3 ) and to test the isolate $\times$ tree interaction (test 3 ). Student-Newman-Keuls tests were used for the pairwise comparison of means. For tests 4 and 5, we studied the effects of isolate, parent tree of the progeny, and their interaction by fitting generalized linear models with a quasi-Poisson error distribution and a log link function to the mortality data, by using the GENMOD procedure of the SAS/STAT software. The scale parameter was estimated by the square root of Pearson's Chi-Square/degrees of freedom.

\section{Results}

Mycelial inoculations. All isolates of $P$. lateralis, regardless of lineage, were pathogenic, causing expanding lesions on at least some wildtype $C$. lawsoniana plants when stem wound inoculated with mycelium (tests 1 and 2). Necrotic lesions formed in nearly all mycelial inoculations while control wounds usually callused with no necrosis, or formed a very limited necrotic area. $P$. lateralis was confirmed by reisolation or PCR diagnostic test in all $(n=130)$ mycelial inoculations where it was checked; 1 of 13 reisolation attempts of control inoculations was contaminated with $P$. lateralis.

The four phylogenetic lineages of $P$. lateralis (1) differed significantly in aggressiveness on the susceptible wildtype trees in tests 1 and 2 (Table 5, Figure 1). Although different isolates were used in the two tests and although average lesion lengths were slightly longer in test 1 than in test 2 (including for the three isolates included in both tests [P2419, LAN2.1, and P2148]), results for the lineages were similar. Average lesion length from PNW lineage isolates, regardless of origin (France or western North America), ranged from 58 to $96 \mathrm{~mm}$ and $96 \%$ of lesions girdled inoculated stems across test 1 and test 2 . Taiwan K (TWK) isolates produced significantly shorter lesions than PNW isolates in both tests ( 20 to $48 \mathrm{~mm}$ average). They girdled about

Table 3. Isolates of Phytophthora lateralis used in this study and their origins

\begin{tabular}{llllr}
\hline Lineage & \multicolumn{1}{c}{ Isolate } & \multicolumn{1}{c}{ Host } & Country & \multicolumn{1}{c}{ Test $^{\mathbf{b}}$} \\
\hline PNW & P2411 & $\begin{array}{l}\text { Chamaecyparis } \\
\text { lawsoniana } \text { roots }\end{array}$ & USA & 1,3 \\
PNW & P2419 (P1 4) & C. lawsoniana roots & USA & $1,2,3,4,5$ \\
PNW & P2422 & C. lawsoniana roots & France & 1,3 \\
PNW & LAN2.1 & C. lawsoniana collar & France & $1,2,3,4$ \\
PNW & MEN1.2 & C. lawsoniana collar & France & 1,3 \\
PNW & MOE1 (P2458) & C. lawsoniana collar & France & 1,3 \\
PNW & SCA3.1 & C. lawsoniana branch & France & 1,4 \\
UK & P2311 & C. lawsoniana & Scotland & $2,4,5$ \\
UK & P2335 & C. lawsoniana & Scotland & 4 \\
TWK & P2145 & C. obtusa soil & Taiwan & 1,3 \\
TWK & P2148 & C. obtusa soil & Taiwan & $1,2,3,4,5$ \\
TWK & P2151 & C. obtusa soil & Taiwan & $1,3,4,5$ \\
TWJ & P2271 & C. obtusa foliage & Taiwan & 2,5 \\
TWJ & P2246 & C. obtusa foliage & Taiwan & 2,5 \\
TWJ & P2279 & C. obtusa foliage & Taiwan & 2 \\
TWJ & P2300 & C. obtusa root \& soil & Taiwan & 2,5 \\
\hline
\end{tabular}

${ }^{a}$ As assigned by Brasier et al. (2012).

b Tests 1 and 2 stem wound inoculations; tests 3, 4, and 5 zoospore dip inoculations.

c Brasier et al. (2012) used other isolates from the same tree to assign lineage.

Table 4. Genetic background of Chamaecyparis lawsoniana plants used in Phytophthora lateralis resistance tests

\begin{tabular}{|c|c|c|c|}
\hline Parent tree & Plant material & Resistance $^{a}$ & Test $^{\mathbf{b}}$ \\
\hline Wildtype & $\begin{array}{l}\text { Seedlings from range-wide collection } \\
\text { of bulk seed from unselected parents }\end{array}$ & Susceptible & 1,2 \\
\hline OSU-SUSC2 & $\begin{array}{l}\text { Clonal - cut branches from trees } \\
\text { derived from rooted cuttings }\end{array}$ & $\begin{array}{l}\text { Susceptible } \\
\text { control }\end{array}$ & 3 \\
\hline OSU-CON1 & $\begin{array}{l}\text { Clonal - cut branches from trees } \\
\text { derived from rooted cuttings }\end{array}$ & $\begin{array}{l}\text { Susceptible } \\
\text { control }\end{array}$ & 3 \\
\hline OSU-CON1 & Seedlings from open pollinated seed & Susceptible & 4 \\
\hline OSU-CON1 & Seedlings from selfed seed & Susceptible & 5 \\
\hline COS30858 & Seedlings from selfed seed & Susceptible & 4,5 \\
\hline COS30722 & Seedlings from selfed seed & Susceptible & 4,5 \\
\hline SIS42266 & Seedlings from selfed seed & Susceptible & 4,5 \\
\hline SIS41427 & $\begin{array}{l}\text { Seedlings from controlled cross } \\
\text { with COS30881 }\end{array}$ & $\begin{array}{l}\text { Susceptible } \\
\times \text { susc. }\end{array}$ & 4 \\
\hline SIS43079 & Seedlings from selfed seed & $\begin{array}{l}\text { Moderate } \\
\text { resistance }\end{array}$ & 4 \\
\hline 117490 & $\begin{array}{l}\text { Clonal - cut branches from trees } \\
\text { derived from rooted cuttings }\end{array}$ & $\begin{array}{c}\text { Resistant } \\
\text { control }\end{array}$ & 3 \\
\hline 117490 & Seedlings from open pollinated seed & Resistant & 4,5 \\
\hline OSU-CF1 & $\begin{array}{l}\text { Clonal - cut branches from trees } \\
\text { derived from rooted cuttings }\end{array}$ & $\begin{array}{c}\text { Resistant } \\
\text { control }\end{array}$ & 3 \\
\hline OSU-CF1 & Seedlings from open pollinated seed & $\begin{array}{l}\text { Moderate } \\
\text { resistance }\end{array}$ & 4,5 \\
\hline 510005 & $\begin{array}{l}\text { Clonal - cut branches from trees } \\
\text { derived from rooted cuttings }\end{array}$ & $\begin{array}{c}\text { Resistant } \\
\text { control }\end{array}$ & 3 \\
\hline SIS42770 & Seedlings from selfed seed & Unknown & 4 \\
\hline SRM13-01 & $\begin{array}{l}\text { Seedlings from controlled cross } \\
\text { with DOR70270 }\end{array}$ & Unknown & 4,5 \\
\hline
\end{tabular}

${ }^{a}$ Resistance level determined in tests by DGRC and OSU (data not shown). "Control" sources are used as resistant and susceptible standards in the breeding program.

b Tests 1 and 2 stem wound inoculations; tests 3,4, and 5 zoospore stem and root dip inoculations. 
Table 5. Analysis of variance for lesion length (in $\mathrm{mm}$ ) measured after stem wound inoculation (tests 1 and 2) of Chamaecyparis lawsoniana wildtype seedlings with isolates of Phytophthora lateralis representing different lineages of the pathogen

\begin{tabular}{lcccccc}
\hline Test & Source & DF & Type III SS & Mean square & F value & $\operatorname{Pr}>$ F \\
\hline 1 & isolate & 9 & 54461.2 & 6051.24 & 27.23 & $<0.0001$ \\
2 & isolate & 7 & 19793.2 & 2827.6 & 12.43 & $<0.0001$ \\
\hline
\end{tabular}

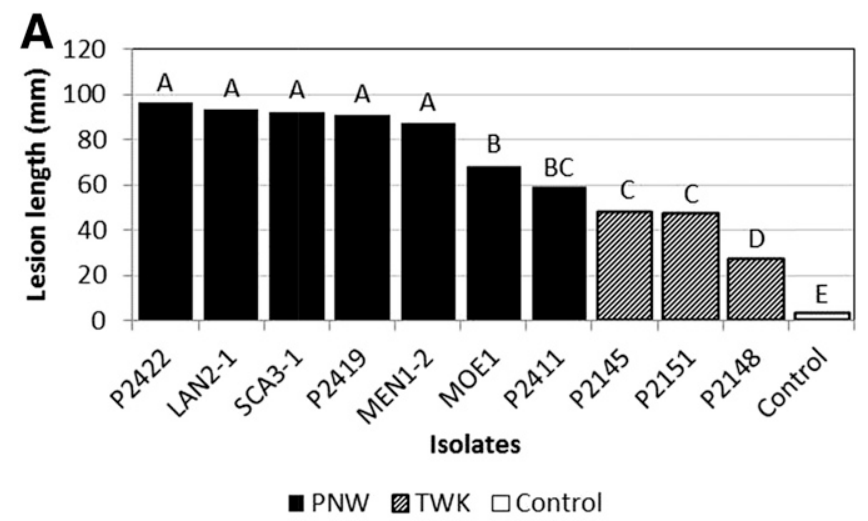

B

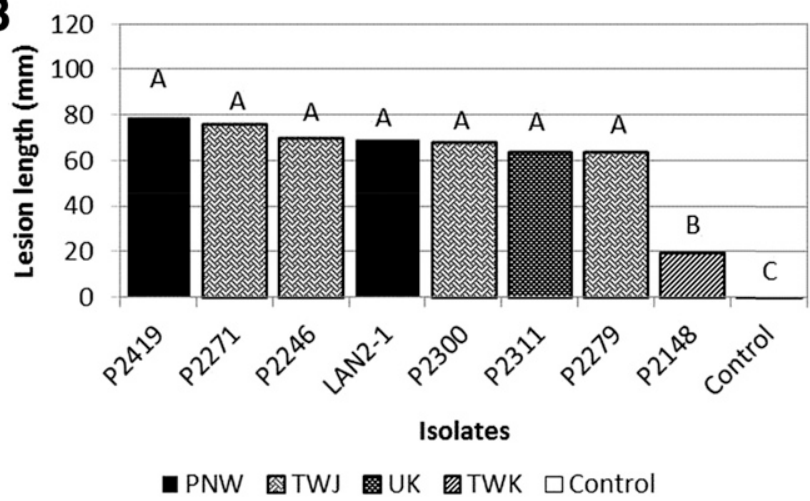

Fig. 1. Lesion length measured after mycelial inoculations (A: test 1, B: test 2) of wildtype Chamaecyparis lawsoniana seedlings with isolates of Phytophthora lateralis representing different lineages of the pathogen. Bars with the same letter are not significantly different.
$40 \%$ of the stems. Lesion lengths and girdling from stem wound inoculations with Taiwan $\mathrm{J}$ (TWJ) isolates ( 63 to $75 \mathrm{~mm}$ ) and the UK lineage $(63 \mathrm{~mm})$ in test 2 were comparable to PNW isolates (Fig. 2, girdling data not shown).

Zoospore inoculations. Zoospore production differed between the lineages: TWK isolates regularly produced fewer zoospores and more slowly than isolates of the other lineages (data not shown). To compensate for that, we attempted to standardize inoculum dose among the different isolates. In the branch stem dip test (test 3), most mock inoculations developed no necrosis at the cut end (average $1.2 \mathrm{~mm}$ ), whereas all $P$. lateralis isolates caused expanding lesions (average $19.8 \mathrm{~mm}$ ). In root dip inoculations tests, $P$. lateralis was confirmed by PCR diagnostic test in $92 \%$ of the inoculated plants ( $n=125$ for test 4$)$ and $99 \%(n=97$ for test 5$)$ where it was checked.

Consistent results were observed for the pathogenicity of the different lineages and the resistance of POC trees, over the three zoospore inoculation tests (tests 3,4 and 5, Table 6). There was a significant interaction term (isolate $\times$ tree) in test 3 on lesion length (Table 7, Fig. 2). However, it resulted from the unusually short lesions produced by one TWK isolate (P2145) on the susceptible standard, the tree OSU-CON1, and the ranking of isolates or trees did not significantly change with the tree or the isolate, respectively. In tests 4 and 5 , the interaction effect was not significant, and the model was fitted with the two main factors ( $P$. lateralis isolate and POC family, Table 8).

There was a significant effect of tree family on lesion length or overall mortality (Tables 7 and 8). Resistant control POC families were resistant to all four $P$. lateralis lineages. Results were also consistent for the resistance of the plants according to their genetic background over the three zoospore inoculation tests (tests 3, 4, and 5, Fig. 3): plants from resistant control families had smaller lesions and exhibited lower mortality rate than plants from susceptible control families. The open pollinated progenies from the two reference resistant trees 117490 and OSU-CF1 behaved differently. For 117490 seedlings, total mortality, which appeared only after 163 days in test 4, was 3\%, whereas in OSU-CF1 families challenged with PNW isolates, mortality rates varied from 20 to $56 \%$ in test 4 and total mortality reached 23 and $30 \%$ in tests 4 and 5, respectively.

There were meaningful differences in aggressiveness among the lineages, whether measured by lesion length or overall mortality (Tables 6 and 7). In branch inoculations (test 3, Fig. 2), lesions from TWK isolates were significantly shorter ( $22 \mathrm{~mm}$ average) on the susceptible control OSU-CON1 than were lesions from PNW isolates

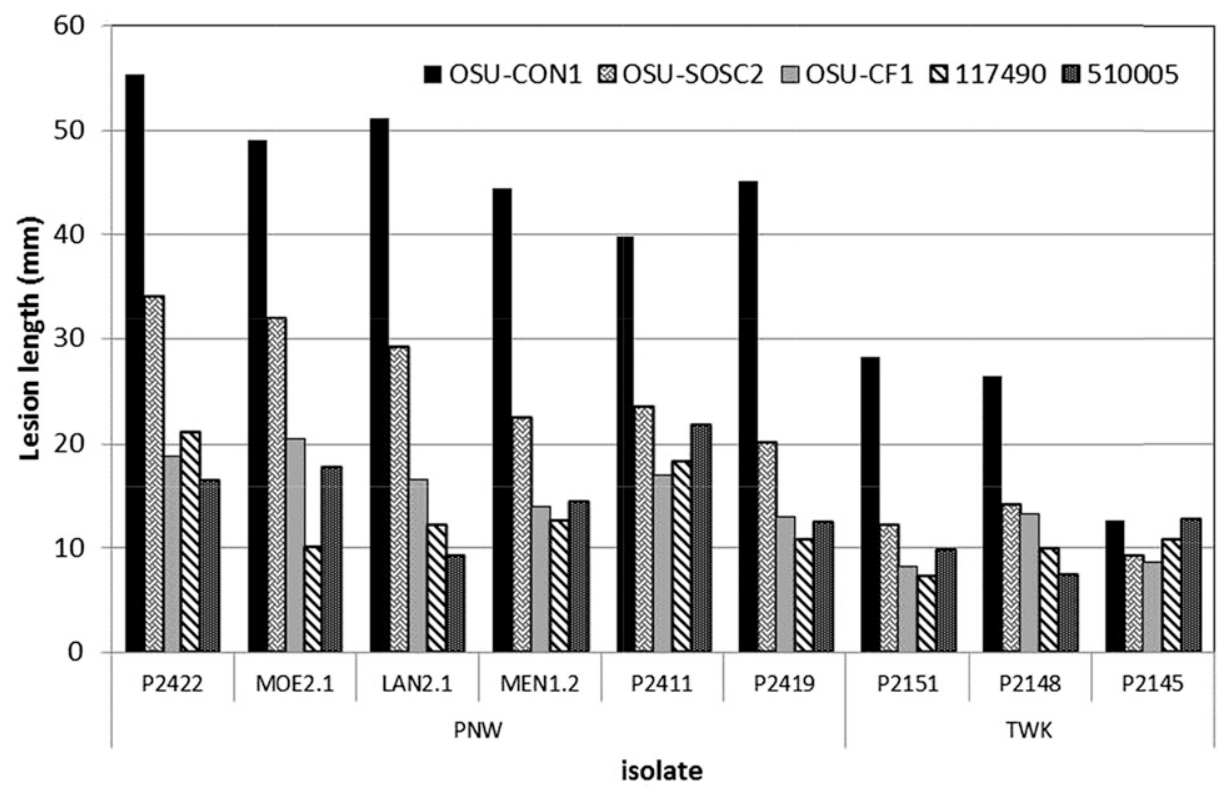

Fig. 2. Lesion length measured after zoospore stem dip inoculation (test 3 ) of susceptible and resistant control seedlings of Chamaecyparis lawsoniana with isolates of Phytophthora lateralis representing different lineages of the pathogen. 
(49 $\mathrm{mm}$ average). In tests 4 and 5, final mortality from TWK isolates on OSU-CON1 seedlings was also lower than mortality from PNW isolates (39 and 20\% on average in tests 4 and 5, respectively, versus 91 and $100 \%$, Fig. 3). The two UK lineage isolates caused a moderate final mortality ( 25 and $75 \%$ in test $4,22 \%$ in test 5 ), intermediate between mortality caused by PNW and TWK isolates. In addition, first mortality was observed more quickly after inoculation with PNW isolates (92 days post inoculation in tests 4 and 5) than with TWK and UK isolates (first mortality after 118 days for one plant challenged by one PNW isolate in test 5, but after 131 days for all other plants inoculated by a PNW or a UK isolate in tests 4 and 5, Fig. 3). The TWJ isolates, previously tested only on wildtype seedlings in test 2 , exhibited comparable aggressiveness whether measured by lesion length or overall mortality to the PNW lineage isolate included in test 5 .

\section{Discussion}

The recent discovery of $P$. lateralis populations in Europe and in Taiwan raised important questions about the pathogen's origins and population structure, as well as the durability of resistance that has been identified in C. lawsoniana growing in the tree's native range in the Pacific Northwest of the United States. In that region, resistant individuals have been identified and characterized through controlled crosses and challenge inoculations with $P$. lateralis isolates from western North America. Resistant selections are incorporated into seed orchards and resistant seed is now available for operational use in western forests (15). It is important to know if newly described lineages of the pathogen from other regions of the world are virulent on the previously resistant genotypes of the host. At this point it appears they are not.

Despite the experimental limitations imposed by availability of isolates, no breakdown of resistance was observed in our tests. POC trees selected for resistance to $P$. lateralis isolates from Oregon and California were also resistant to newer isolates from France, the UK, and Taiwan, regardless of lineage. Necrosis on resistant stems, such as 117490 , was limited to the $1 \mathrm{~cm}$ that was exposed to zoospores when challenged with Taiwan $\mathrm{K}$ lineage isolates, or extended a limited distance up the stem (less than $2 \mathrm{~cm}$ ) when challenged with French or American PNW isolates or the TWJ lineage, while lesions on branch ends from the susceptible control tree OSU-CON1 continued to expand, less than $2 \mathrm{~cm}$ (when challenged with TWK isolates) or more than $3 \mathrm{~cm}$ in test 3 (when challenged with the PNW isolates).

Table 6. Average lesion length (test 3 , five resistant and susceptible control families) and total mortality (test 4, 10 families; and test 5, seven families) of Chamaecyparis lawsoniana seedlings induced by Phytophthora lateralis after stem or root dip inoculation with zoospore suspensions

\begin{tabular}{lcccc}
\hline Isolate & Lineage $^{\mathbf{a}}$ & $\begin{array}{c}\text { Lesion length }^{\mathbf{b}} \\
(\mathbf{m m})(\mathbf{t e s t} 3)\end{array}$ & $\begin{array}{c}\text { Mortality } \\
(\boldsymbol{\%})^{\mathbf{b}} \text { (test 4) }\end{array}$ & $\begin{array}{c}\text { Mortality } \\
(\boldsymbol{\%})^{\mathbf{b}} \text { (test 5) }\end{array}$ \\
\hline P2411 & PNW & 22.3 & $-c$ & - \\
P2419 (P1 4) & PNW & 20.3 & 54 & 67 \\
P2422 & PNW & 28.3 & - & - \\
LAN2.1 & PNW & 23.9 & 61 & - \\
MEN1.2 & PNW & 20.7 & - & - \\
MOE 1 & PNW & 25.4 & - & - \\
SCA3.1 & PNW & - & 63 & - \\
P2311 & UK & - & 14 & 17 \\
P2335 & UK & - & 5 & - \\
P2145 & TWK & 10.4 & - & - \\
P2148 & TWK & 14.2 & 2 & 2 \\
P2151 & TWK & 12.8 & 10 & 11 \\
P2271 & TWJ & - & - & 69 \\
P2246 & TWJ & - & - & 66 \\
P2279 & TWJ & - & - & - \\
P2300 & TWJ & - & - & 62 \\
Control & & 1.2 & 0 & 0 \\
\hline
\end{tabular}

a Brasier et al. (2012).

b Overall average of all seedling families.

c Isolate not included in this test.
The resistance observed for the open pollinated progenies of 117490 (tests 4 and 5) confirmed the hypothesis of the presence of a single dominant gene in this tree. In contrast, segregation for this character is suggested by results obtained for OSU-CF1 progenies, in agreement with previous reports (12).

Isolates from France, assigned to the PNW lineage (1), had a very similar pathogenicity profile on resistant and susceptible POC to the PNW lineage isolates from Oregon. TWK isolates were notable for their consistently lower aggressiveness in the several tests. Indeed, the two Taiwan lineages, TWK and TWJ, exhibited different levels of pathogenicity, the TWJ isolates being as aggressive as PNW isolates. The limited evidence for host genotype $\times$ pathogen lineage interaction suggests an overall low aggressiveness for the TWK lineage. The two UK lineage isolates tested differed substantially in pathogenicity on the susceptible control tree OSU-CON1, although they were more similar to each other and to the TWK isolates in mortality rate on other seedling families (test 4, Fig. 3A). These two isolates represent two different colony types, 'M2' and 'M3,' observed within the UK lineage (1). The possibility that the 'M2' and 'M3' types differ in pathogenicity requires investigation with additional isolates.

Differences in pathogenicity (mortality and lesion length) between the lineages observed here may represent in part the in planta expression of their in vitro growth rate differences (see Table 1). TWK isolates were the slowest growing in vitro (1), and in this study were the slowest to develop within the seedlings after inoculation. TWK isolates also caused significantly lower mortality in seedling inoculations after 21 to 27 weeks (tests 4 and 5). However, it should be noted that mortality with TWK started later than with PNW isolates and had not yet plateaued on susceptible tree genotypes OSU-CON1 and SRM13 at the end of the test. On the resistant tree genotypes, TWK isolates caused no mortality through the duration of the study. They also produced sporangia and zoospores more slowly and less prolifically than those of the other lineages. In contrast, TWJ isolates induced lesions as long as those of PNW isolates (Fig. 2), even though these isolates are as slow growing as TWK isolates in vitro (1). They also produced sporangia and zoospores at a similar rate to PNW isolates in this study.

The possibility that other sources of variation in aggressiveness might have influenced these results must be acknowledged. Differential isolate by environment reactions are known from other pathosystems, including the closely related $P$. ramorum (3). The broad consistency of the results reported here across isolates within a lineage, different inoculation methods, different resistance sources, and repeated tests lends support to our conclusions, however.

As discussed by Brasier and colleagues $(1,2)$, the history of spread and evolutionary history of the $P$. lateralis lineages, including the

Table 7. Results of the analysis of variance of lesion length (in $\mathrm{mm}$ ) measured after zoospore stem dip inoculation (test 3) of susceptible and resistant seedlings of Chamaecyparis lawsoniana with isolates of Phytophthora lateralis representing different lineages of the pathogen

\begin{tabular}{lrccrc}
\hline Source & DF & Type III SS & Mean square & F value & Pr $>$ F \\
\hline Isolate & 9 & 11999.1 & 1499.89 & 26.52 & $<0.0001$ \\
Tree & 4 & 48963.6 & 1499.89 & 216.46 & $<0.0001$ \\
Isolate $\times$ tree & 32 & 9717.3 & 303.66 & 5.37 & $<0.0001$ \\
\hline
\end{tabular}

Table 8. Results of generalized linear models analyzing the effect of Phytophthora lateralis representing different lineages of the pathogen and Chamaecyparis lawsoniana seedlings representing host genetic background on plant mortality after zoospore root dip tests (tests 4 and 5)

\begin{tabular}{llccrcrc}
\hline Test & Source & DF num & DF res & \multicolumn{1}{c}{ F } & P $>$ F & Chi-2 & Pr $>$ Chi-2 \\
\hline 4 & Isolate & 6 & 54 & 28.43 & $<0.0001$ & 170.56 & $<0.0001$ \\
& Host & 9 & 54 & 8.92 & $<0.0001$ & 80.26 & $<0.0001$ \\
5 & Isolate & 6 & 36 & 39.42 & $<0.0001$ & 236.52 & $<0.0001$ \\
& Host & 6 & 36 & 28.68 & $<0.0001$ & 172.09 & $<0.0001$ \\
\hline
\end{tabular}


A Test 4

\section{0}

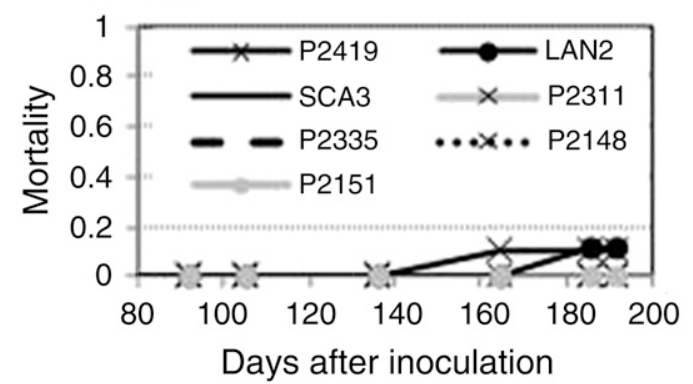

OSU-CF1

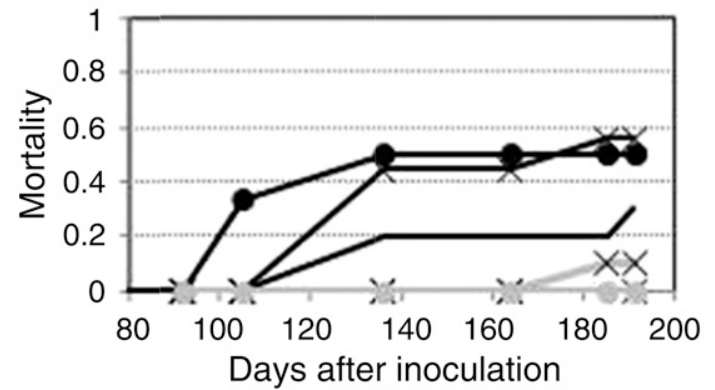

OSU-CON1

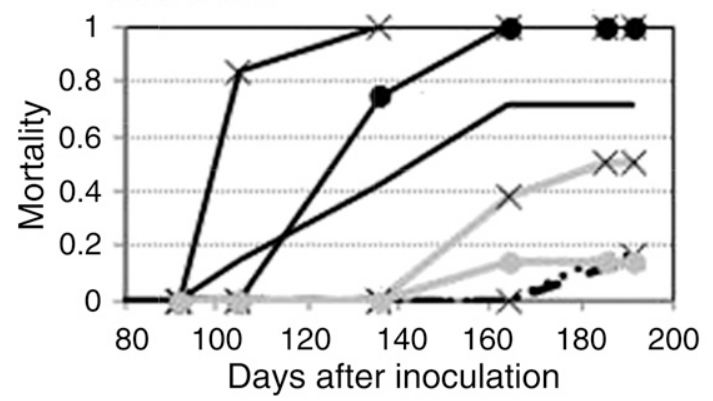

B Test 5

117490
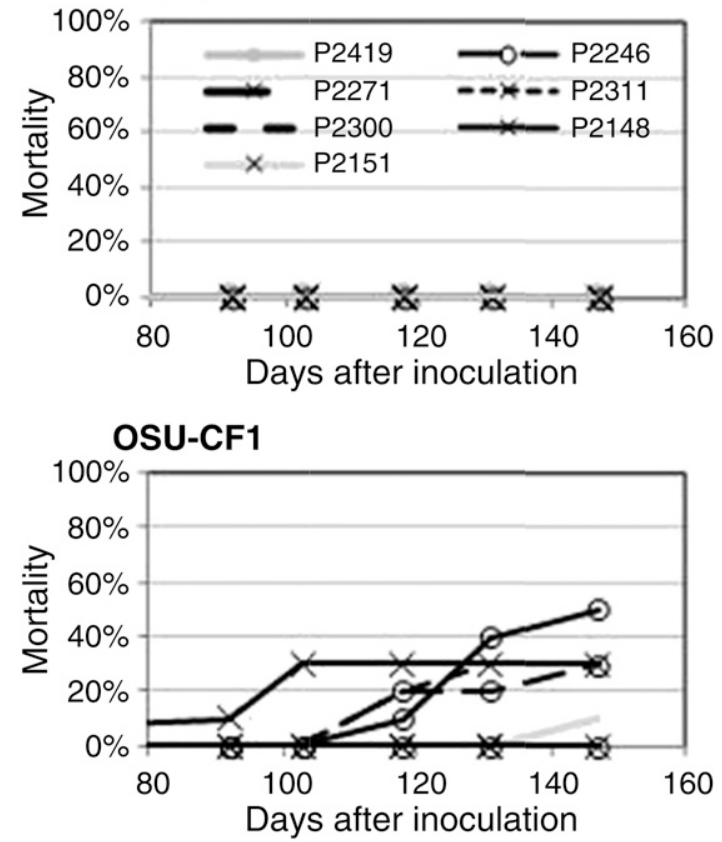

OSU-CON1

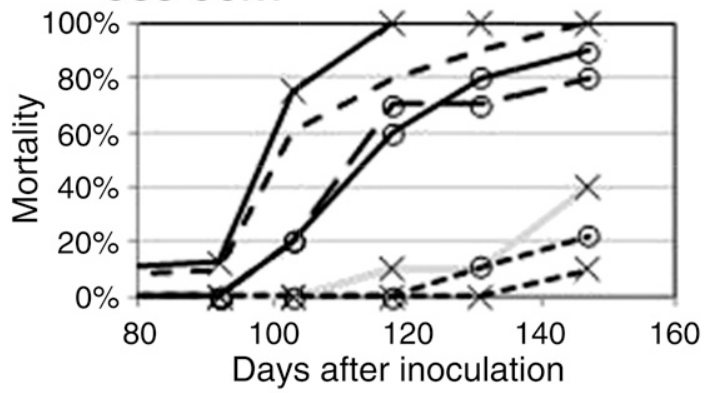

Fig. 3. Cumulative mortality (\%) of susceptible (OSU-CON1) and resistant (117490, OSU-CF1) Chamaecyparis lawsoniana seedling families induced by isolates of Phytophthora lateralis representing different lineages with days after inoculation by zoospore root dip suspensions (A: test 4, B: test 5).

identity of the presumed Asian progenitor of the environmentally damaging PNW lineage, remain uncertain. Brasier et al. (1) argued that two forms as adaptively different as the Taiwanese TWJ and TWK lineages would be unlikely to be able to coexist in Taiwan and suggested that TWK may be native to Taiwan and TWJ a recent introduction, e.g., from Japan. The contrasting higher and lower aggressiveness of the TWJ and TWK lineages observed here adds further support to this view. Furthermore, the fact that in the present tests the PNW isolates showed a similar high level of aggressiveness to the Taiwanese TWJ isolates adds further support to another suggestion by Brasier et al. (1) that the form of $P$. lateralis introduced into the Pacific Northwest in the early 20th century may have been the TWJ lineage, which then evolved into the much faster growing but morphologically similar PNW lineage on the highly susceptible $C$. lawsoniana population. The comparable higher level of pathogenicity of the French and North American PNW isolates is consistent with the view derived from molecular and morphological similarity (1) that the French isolates, and by analogy other European PNW isolates, were probably introduced into Europe from North America $(1,8)$.

\section{Acknowledgments}

We thank Richard Sniezko and the DGRC, and Ellen Goheen, Southwestern Oregon Service Center, USDA Forest Service, for seedlings and financial support. Travel and support for Cécile Robin was provided by the COST Action "FP0801 Established and Emerging Phytophthora: Increasing Threats to Woodland and Forest Ecosystems in Europe."

\section{Literature Cited}

1. Brasier, C. M., Vettraino, A. M., Chang, T. T., and Vannini, A. 2010. Phytophthora lateralis discovered in an old growth Chamaecyparis forest in Taiwan. Plant Pathol. 59:595-603.

2. Brasier, C. M., Franceschini, S., Vettraino, A. M., Hansen, E. M., Green, S., Robin, C., Webber, J. F., and Vannini, A. 2012. Four phenotypically and phylogenetically distinct lineages in Phytophthora lateralis. Fungal Biol. 116:1232-1249.

3. Eyre, C. A., Hayden, K. J., Kozanitas, M., Grünwald, N. J., and Garbelotto, M. 2014. Lineage, temperature, and host species have interacting effects on lesion development in Phytophthora ramorum. Plant Dis. 98:1717-1727.

4. Green, S., Brasier, C. M., Schlenzig, A., McCracken, A., MacAskill, G. A., Wilson, M., and Webber, J. F. 2013. The destructive invasive pathogen Phytophthora lateralis found on Chamaecyparis lawsoniana across the UK. For. Pathol. 43:19-28.

5. Hansen, E. M., Hamm, P. B., and Roth, L. F. 1989. Testing Port Orford cedar for resistance to Phytophthora. Plant Dis. 73:791-794.

6. Hansen, E. M., Streito, C., and Delatour, C. 1999. First confirmation of Phytophthora lateralis in Europe. Plant Dis. 83:587.

7. Hansen, E. M., Goheen, D. J., Jules, E. S., and Ullian, B. 2000. Managing PortOrford-cedar and the introduced pathogen Phytophthora lateralis. Plant Dis. $84: 4-14$.

8. Hansen, E., Reeser, P., Sutton, W., and Sniezko, R. 2012. Methods for Screening Port-Orford-Cedar for Resistance to Phytophthora lateralis. Pages 181-188 in: Proceedings of the 4th International Workshop on Genetics of Host-Parasite Interactions in Forestry, Eugene, Oregon. K. M. Palmieri, tech. coord. Gen. Tech. Rep. PSW-GTR-240. U.S. Department of Agriculture, Forest Service, Pacific Southwest Research Station, Albany, CA

9. Jules, E. S., Kauffman, M. J., Ritts, W. D., and Carroll, A. L. 2002. Spread of an invasive pathogen over a variable landscape: A nonnative root rot on Port Orford cedar. Ecology 83:3167-3181. 
10. Meffert, J. P. 2013. Pest risk assessment for Phytophthora lateralis. Netherlands Food and Public Safety Authority, online: www.vwa.nl/ txmpub/files/?p_file_id=2204533.

11. Oh, E., and Hansen, E. A. 2007. Histopathology of infection and colonization of susceptible and resistant Port-Orford-cedar by Phytophthora lateralis. Phytopathology 97:684-693.

12. Oh, E., Hansen, E. M., and Sniezko, R. A. 2006. Port-Orford-cedar resistant to Phytophthora lateralis. For. Pathol. 36:385-394.

13. Robin, C., Piou, D., Feau, N., Douzon, G., Schenck, N., and Hansen, E. M. 2011. Root and aerial infections of Chamaecyparis lawsoniana by Phytophthora lateralis: a new threat for European countries. For. Pathol. 41:417-424.

14. Roth, L. F., Trione, E. J., and Ruhmann, W. H. 1957. Phytophthora induced root rot of native Port-Orford-cedar. J. For. 55:294-298.

15. Sniezko, R. A., Hamlin, J., and Hansen, E. M. 2012. Operational program to develop Phytophthora lateralis-resistant populations of Port-Orford-cedar (Chamaecyparis lawsoniana). Pages 65-79 in: Proceedings of the 4th International Workshop on Genetics of Host-Parasite Interactions in Forestry, Eugene, Oregon. K. M. Palmieri, tech. coord. Gen. Tech. Rep. PSW-GTR-240. U.S. Department of Agriculture, Forest Service, Pacific Southwest Research Station, Albany, CA
16. Trione, E. J., and Roth, L. F. 1957. Aerial infection of Chamaecyparis by Phytophthora lateralis. Plant Dis. Rep. 41:211-215.

17. Tucker, C. M., and Milbrath, J. A. 1942. Root rot of Chamaecyparis caused by a species of Phytophthora. Mycologia 34:94-101.

18. USDA-FS, and USDI-BLM. 2004. Final Supplemental Environmental Impact Statement - Management of Port-Orford-Cedar in Southwest Oregon, Portland OR. http://www.fs.usda.gov/detail/rogue-siskiyou/landmanagement/? cid=stelprdb5316256.

19. USDA-FS, and USDI-BLM. 2003. A Range-wide Assessment of Port-OrfordCedar (Chamaecyparis lawsoniana) on Federal Lands, http://www.fs.usda gov/Internet/FSE_DOCUMENTS/stelprdb5316517.pdf Page 182, P. Oregon/ Washington State Office, OR, ed.

20. Webber, J. F., Vettraino, A. M., Chang, T. T., Bellgard, S. E., Brasier C. M., and Vannini, A. 2012. Isolation of Phytophthora lateralis from Chamaecyparis foliage in Taiwan. For. Pathol. 42:136-143.

21. Zobel, D. B., Roth, L. F., and Hawk, G. M. 1985. Ecology, pathology and management of Port-Orford-Cedar (Chamaecyparis lawsoniana). Page 16 in: General Technical Report of the Pacific Northwest Forest Range Experiment Station USDA Forest Service No. PNW-184. 